\title{
Benzodiazepines are Prescribed More Frequently to Patients Already at Risk for Benzodiazepine-Related Adverse Events in Primary Care
}

\author{
David S. Kroll, MD ${ }^{1,2}$, Harry Reyes Nieva, BA ${ }^{1,3}$, Arthur J. Barsky, MD ${ }^{1,2}$, and Jeffrey A. Linder, MD ${ }^{1,3}$ \\ 'Harvard Medical School, Boston, MA, USA; ${ }^{2}$ Department of Psychiatry, Brigham and Women's Hospital, Boston, MA, USA; ${ }^{3}$ Division of General \\ Medicine and Primary Care, Brigham and Women's Hospital, Boston, MA, USA.
}

\begin{abstract}
BACKGROUND: Benzodiazepine use is associated with adverse drug events and higher mortality. Known risk factors for benzodiazepine-related adverse events include lung disease, substance use, and vulnerability to fracture. OBJECTIVE: To determine whether benzodiazepine prescribing is associated with risk factors for adverse outcomes.
\end{abstract}

DESIGN: Longitudinal cohort study between July 1, 2011, and June 30, 2012.

PARTICIPANTS: Patients who visited hospital- and community-based practices in a primary care practicebased research network.

MAIN MEASURES: Odds ratio of having a target medical diagnosis for patients who received standard and highdose benzodiazepine prescriptions; rates per 100 patients for outpatient and emergency department visits and hospitalizations.

KEY RESULTS: Among 65,912 patients, clinicians prescribed at least one benzodiazepine to $15 \%$ (9821). Of benzodiazepine recipients, $5 \%$ received high doses. Compared to non-recipients, benzodiazepine recipients were more likely to have diagnoses of depression (OR, 2.7; $95 \%$ CI, 2.6-2.9), substance abuse (OR, 2.2; $95 \%$ CI, 1.9-2.5), tobacco use (OR, 1.7; $95 \%$ CI, 1.5-1.8), osteoporosis (OR, 1.6; $95 \%$ CI, 1.5-1.7), chronic obstructive pulmonary disease (OR, 1.6; $95 \%$ CI, 1.5-1.7), alcohol abuse (OR, 1.5; $95 \%$ CI, 1.3-1.7), sleep apnea (OR, 1.5; $95 \%$ CI, 1.31.6), and asthma (OR, 1.5; $95 \%$ CI, 1.4-1.5). Compared to low-dose benzodiazepine recipients, high-dose benzodiazepine recipients were even more likely to have certain medical diagnoses: substance abuse (OR, 7.5; $95 \% \mathrm{CI}$, 5.5-10.1), alcohol abuse (OR, 3.2; 95 \% CI, 2.2-4.5), tobacco use (OR, 2.7; $95 \%$ CI, 2.1-3.5), and chronic obstructive pulmonary disease (OR, 1.5; $95 \%$ CI, 1.2-1.9).

Previous Presentations Preliminary data from this study were presented at the 61st Annual Meeting of the Academy of Psychosomatic Medicine, Fort Lauderdale, Florida, November 14, 2014; additional data will be presented in part at the 62nd Annual Meeting of the Academy of Psychosomatic Medicine, New Orleans, Louisiana, November 13, 2015.

Electronic supplementary material The online version of this article (doi:10.1007/s11606-016-3740-0) contains supplementary material, which is available to authorized users.

Received October 20, 2015

Revised March 31, 2016

Accepted May 2, 2016

Published online May 13, 2016
Benzodiazepine recipients had more primary care visits per 100 patients ( 408 vs. 323), specialist outpatient visits (815 vs. 578), emergency department visits (47 vs. 29), and hospitalizations (26 vs. $15 ; p<.001$ for all comparisons).

CONCLUSIONS: Clinicians prescribed benzodiazepines and high-dose benzodiazepines more frequently to patients at higher risk for benzodiazepine-related adverse events. Benzodiazepine prescribing was associated with increased healthcare utilization.

KEY WORDS: psychopharmacology; benzodiazepines; anxiety; sleep disorders.

J Gen Intern Med 31(9):1027-34

DOI: $10.1007 /$ s11606-016-3740-0

(C) Society of General Internal Medicine 2016

\section{INTRODUCTION}

Benzodiazepines are commonly used to treat anxiety and sleep disorders, as well as a number of primary medical conditions. However, they are often prescribed to patients who either do not have a clear indication ${ }^{1}$ or have poor indications such as depression. $^{2}$

The use of benzodiazepines is associated with higher mortality. ${ }^{3,4}$ National registries in Europe and the United States have linked benzodiazepines use to elevated rates of respiratory suppression in patients with chronic obstructive pulmonary disease $(\mathrm{COPD})^{5}$ and with overdose death in substance use disorders. ${ }^{6,7}$ Benzodiazepines may also be linked to cancer risk and to exacerbation of obstructive sleep apnea (OSA) severity. ${ }^{8,9}$ In the elderly, benzodiazepines are associated with delirium in the hospital ${ }^{10,11}$ and with hip fractures, ${ }^{12}$ disability, ${ }^{13}$ and dementia ${ }^{14,15}$ in the community.

Although benzodiazepines are frequently prescribed by primary care physicians (PCPs), ${ }^{16}$ few studies have described in detail which primary care patients receive benzodiazepine prescriptions. Most studies that have explored this question were performed outside of North America. ${ }^{17-26}$ These works identified some demographic predictors of benzodiazepine prescription (e.g., increased age and female gender) and an association with higher medical comorbidity in general, but did not focus on specific medical diagnoses. While benzodiazepines have known risks of adverse events in the elderly, including fractures, and in patients with lung disease and 
substance use disorders, no prior studies have examined benzodiazepine prescriptions within the distribution of conditions that increase the risk of benzodiazepine-related adverse events in primary care in North America.

We hypothesized that clinicians prescribe benzodiazepines disproportionately to primary care patients with factors or diagnoses that increase the risk of benzodiazepine-related adverse events, and that patients who receive benzodiazepines have higher healthcare utilization rates. If confirmed, such risk factors and utilization rates could explain some of the association between benzodiazepine use and higher mortality. We performed a longitudinal cohort study to identify associations between benzodiazepine prescribing, risk factors for benzodiazepine-related adverse events, and healthcare utilization.

\section{METHODS}

\section{Setting}

The Brigham and Women's Primary Care Practice-Based Research Network (BWPC PBRN) includes 16 hospital- and community-based practices and community health centers in eastern Massachusetts. The BWPC PBRN practices used a fully functional, Certification Commission for Healthcare Information Technology (CCHIT)-certified electronic health record (EHR), which included problem lists, medication lists, and prescriptions. By policy, all medicines were prescribed through the EHR. Medications not prescribed by affiliated clinicians were listed in the EHR without dosing information.

Sociodemographic information was collected during registration and was updated periodically. Billing codes were recorded in a separate, dedicated billing system. Partners HealthCare - an integrated health delivery system in eastern Massachusetts, of which Brigham and Women's Hospital is a part - had an information system that captured outpatient visits, emergency room visits, and hospitalizations for all Partners HealthCare facilities.

Approval for the conduct of this study was obtained from the Partners HealthCare Institutional Review Board.

\section{Data Extraction}

We used the Partners HealthCare Research Patient Data Repository, which aggregates data from throughout Partners HealthCare facilities, to identify all patients who made at least one visit to any of the ten BWPC PBRN practices that were participating in an unrelated clinical trial between July 1, 2011, and June 30, 2012. ${ }^{27-29}$ We extracted and combined sociodemographic and clinical information from the EHR with billing codes.

We included all coded benzodiazepine prescriptions and listings. From the EHR we extracted prescription details that included the name of the medication, dose, frequency, total number of units prescribed, number of refills, and prescribing clinician. Our data source included prescriptions; we could not measure prescription fills or actual benzodiazepine use by patients.

We extracted medical diagnoses from the EHR problem list and ICD-9 billing codes associated with individual encounters (see online appendix). We extracted medical diagnoses defined by the Healthcare Effectiveness Data and Information Set (HEDIS; asthma, COPD, cardiovascular disease, depression, diabetes, hypertension, obesity, osteoporosis, and tobacco use), ${ }^{30}$ psychiatric diagnoses for which benzodiazepines are commonly prescribed (anxiety and insomnia), and diagnoses for which benzodiazepines are contraindicated or controversial (alcohol abuse, sleep apnea, and substance abuse). ${ }^{6,7,9,31}$

We also extracted data about antidepressant medication prescribing from the EHR, because these are commonly considered first-line agents for depression and anxiety. We included the antidepressants fluoxetine, sertraline, paroxetine, citalopram, escitalopram, fluvoxamine, mirtazapine, bupropion, venlafaxine, desvenlafaxine, duloxetine, nefazodone, amitriptyline, amoxapine, clomipramine, desipramine, doxepin, imipramine, nortriptyline, protriptyline, trimipramine, phenelzine, tranylcypromine, isocarboxazid, trazodone, and vilazodone.

We extracted medical encounters from encounter-level billing data, including primary care visits (both any visit to the primary care clinic and any visit with the PCP of record), specialist outpatient visits, emergency department (ED) visits, and hospitalizations, and length of stay for patients with one or more hospitalizations. We defined a patient's PCP as the PCP of record from the EHR. Listed PCPs are nearly always primary care clinicians.

\section{Data Analysis}

We calculated benzodiazepine dosing and days prescribed based on a combination of pill dose/strength, dosing frequen$\mathrm{cy}$, and number of pills prescribed during the study period. We converted prescriptions of lorazepam, clonazepam, and alprazolam - which, together with diazepam, accounted for $97 \%$ of benzodiazepine prescriptions - to "average daily diazepamequivalent dosages." Only days for which benzodiazepines were prescribed were included in the calculation of average daily dose.

High-dose benzodiazepine prescribing has been defined in the literature as a daily dose equivalent of $\geq 30 \mathrm{mg}$ per day of diazepam. ${ }^{32}$ Although potency equivalence between benzodiazepine agents is not clearly established, we defined $30 \mathrm{mg}$ diazepam equivalents as $3 \mathrm{mg} / \mathrm{d}$ alprazolam, $3 \mathrm{mg} / \mathrm{d}$ clonazepam, and $5 \mathrm{mg} / \mathrm{d}$ lorazepam. ${ }^{32,33}$ For patients with multiple benzodiazepine agents ( $3 \%$ of patients receiving benzodiazepines) for which diazepam-equivalent dosing could be calculated, we added them together as though they were concurrent or consecutive prescriptions of a single diazepam-equivalent agent. Other benzodiazepine prescriptions and benzodiazepine prescriptions without complete prescribing information were not included in the comparison between high-dose and standard-dose prescriptions. 
To determine which patients were most likely to receive benzodiazepine prescriptions, we compared patients who received at least one benzodiazepine prescription with those who did not. We assessed differences in demographic variables, medical diagnoses, and inpatient and outpatient encounters. Among benzodiazepine recipients, we made parallel comparisons between patients who did and did not receive high-dose prescriptions.

\section{Statistical Analysis}

We used means, medians, percentages, odds ratios, and rate ratios with $95 \%$ confidence intervals to compare patients who did and did not receive benzodiazepines and those who received high doses versus standard doses. We compared categorical variables using the chi-square test and continuous variables using Student's $t$ test. We performed the MannWhitney-Wilcoxon test to compare days dosed among categorical variables with two groups and the Kruskal-Wallis test for the same comparison among categorical variables with three or more groups. We calculated odds ratios using logistic regression, and we used Poisson regression to calculate rate ratios. We used SAS software (version 9.3; Cary, NC) for all analyses and considered $p$ values $<0.05$ statistically significant.

\section{RESULTS}

\section{Cohort Characteristics}

Among 65,912 patients who visited one of the ten included primary care practices during the study year, at least one benzodiazepine prescription was issued to $15 \%$ (9821); of these patients, $44 \%$ received at least one benzodiazepine prescription from their PCPs of record as opposed to other providers within or outside their primary care practices. Among the 9821 patients who received a benzodiazepine prescription, the mean age was 55 years, $77 \%$ were white, $7 \%$ were black, and $59 \%$ had private insurance. Patients received a median of $30(\mathrm{IQR}=10-60)$ days of benzodiazepines at a mean daily diazepam dose equivalent of $11 \mathrm{mg}$. There were 9532 (97\%) patients who received only one type of benzodiazepine agent during the study period, $280(3 \%)$ who received two, eight $(<1 \%)$ who received three, and one $(<1 \%)$ who received more than three. The most commonly prescribed benzodiazepines were lorazepam $(n=5057$; $51 \%$;), clonazepam $(n=2007 ; 20 \%)$, diazepam $(n=1372$; $14 \%$ ), and alprazolam ( $n=1371 ; 14 \%)$. The mean daily dose prescribed, by benzodiazepine, was $1.7 \mathrm{mg}$ for lorazepam (10.0 $\mathrm{mg}$ diazepam-equivalent), $1.5 \mathrm{mg}$ for clonazepam (14.5 mg diazepam-equivalent), $10.8 \mathrm{mg}$ for diazepam, and $1.0 \mathrm{mg}$ for alprazolam (10.1 mg diazepam-equivalent).

\section{Benzodiazepine Prescribing}

Clinicians prescribed benzodiazepines more commonly to patients who were older, were women, had Medicare or
Medicaid insurance, and were divorced, widowed, or separated (Table 1). Clinicians prescribed to white patients at a higher rate than to non-white patients. Medical diagnoses associated with a higher likelihood of being prescribed a benzodiazepine included substance abuse, depression, tobacco use, alcohol abuse, osteoporosis, chronic obstructive pulmonary disease (COPD), sleep apnea, and asthma. Clinicians prescribed a higher median days dosed to Medicare recipients and a lower median days dosed to black patients. Only $43 \%$ of patients who were prescribed a benzodiazepine had a diagnosis of anxiety or insomnia noted on a problem list or coded in billing data, and $44 \%$ were concurrently prescribed antidepressants.

Patients to whom benzodiazepines were prescribed were higher users of medical care. On average, they made more primary care, specialist outpatient, and emergency department visits, were hospitalized more frequently, and when hospitalized, had a slightly longer length of stay (Table 2).

\section{High-Dose Benzodiazepine Prescribing}

Among patients with benzodiazepine prescriptions, the PCPs of record prescribed high doses to $5 \%$, including to $3 \%$ of lorazepam recipients, $9 \%$ of clonazepam recipients, $2 \%$ of diazepam recipients, and $6 \%$ of alprazolam recipients. Other clinicians prescribed high doses to $5 \%$ of lorazepam recipients, $10 \%$ of clonazepam recipients, $3 \%$ of diazepam recipients, and $6 \%$ of alprazolam recipients.

Demographic characteristics associated with a higher likelihood of being prescribed a high-dose benzodiazepine included younger age, male gender, Medicaid insurance, nonmarried status, and lower education level (Table 3). Medical diagnoses associated with a higher likelihood of receiving a high-dose benzodiazepine prescription included alcohol abuse, anxiety, asthma, COPD, depression, diabetes, obesity, substance abuse, and tobacco use. Among patients with highdose prescriptions, $52 \%$ were concurrently prescribed antidepressants.

On average, patients who received high-dose benzodiazepine prescriptions had a greater number of emergency visits and hospitalizations compared to patients who received standard-dose prescriptions (Table 2).

\section{DISCUSSION}

Benzodiazepine prescriptions come from multiple sources within the healthcare system, including PCPs, specialists, and ED and inpatient clinicians. In our sample, close to half of the patients who received benzodiazepine prescriptions received at least one from their PCPs, reflecting the relevance of benzodiazepine prescribing among clinicians who work in primary care. Benzodiazepines have a well-established role in the treatment of several conditions commonly seen in primary care, including anxiety and insomnia, and it is likely that benzodiazepine prescribing is safe for many patients, 
Table 1 Patient Characteristics by Benzodiazepine Prescription and Days Dosed

\begin{tabular}{|c|c|c|c|c|c|c|}
\hline Characteristic & $\begin{array}{l}\text { Benzodiazepine } \\
\text { prescription } \\
(n=9821)\end{array}$ & $\begin{array}{l}\text { No benzodiazepine } \\
\text { prescription } \\
(n=\mathbf{5 6 , 0 9 1 )}\end{array}$ & $\begin{array}{l}\text { Odds ratio } \\
(95 \% \mathrm{CI})\end{array}$ & $P$ value & Days dosed & $P$ value \\
\hline & Mean $( \pm$ SD $)$ & & & & & \\
\hline Patient age, years & $55(15)$ & $52(17)$ & $1.12(1.10-1.13)^{*}$ & $<0.001$ & $\mathrm{n} / \mathrm{a}$ & \\
\hline Number of medications & $\begin{array}{l}1.83(1.48) \\
\mathrm{N}(\text { column \%) }\end{array}$ & $1.06(1.33)$ & $1.39(1.37-1.41)$ & $<0.001$ & $\begin{array}{l}\mathrm{n} / \mathrm{a} \\
\text { Median (IQR) }\end{array}$ & \\
\hline Patient gender & & & & $<0.001$ & & $<0.001$ \\
\hline Men & $2699(27)$ & $20,732(37)$ & Referent & & $30(14-90)$ & \\
\hline Women & $7122(73)$ & $35,359(63)$ & $1.55(1.48-1.62)$ & & $30(10-60)$ & \\
\hline Patient race/ethnicity & & & & $<0.001$ & & $<0.001$ \\
\hline White $^{\dagger}$ & 7607 (77) & $36,110(64)$ & Referent & & $30(12-75)$ & \\
\hline Black & $687(7)$ & $7182(13)$ & $0.45(0.42-0.49)$ & & $20(7.5-40)$ & \\
\hline Hispanic & $715(7)$ & $5588(10)$ & $0.61(0.56-0.66)$ & & $30(10-60)$ & \\
\hline Asian & $122(1)$ & $2165(4)$ & $0.27(0.22-0.32)$ & & $30(15-90)$ & \\
\hline Other & $71(1)$ & $583(1)$ & $0.58(0.45-0.74)$ & & $30(10-60)$ & \\
\hline Unknown & $619(6)$ & $4463(8)$ & $0.66(0.60-0.72)$ & & $30(10-60)$ & \\
\hline Language & & & & $<0.001$ & & 0.009 \\
\hline English & $9203(94)$ & $51,093(91)$ & Referent & & $30(10-60)$ & \\
\hline Spanish & $153(2)$ & $2756(5)$ & $0.76(0.68-0.84)$ & & $30(15-90)$ & \\
\hline Other & 375 (4) & $1603(3)$ & $0.53(0.45-0.63)$ & & $30(15-90)$ & \\
\hline Unknown & $90(1)$ & 639 (1) & $0.78(0.63-0.98)$ & & $30(15-60)$ & \\
\hline Insurance & & & & $<0.001$ & & $<0.001$ \\
\hline Private & $5842(59)$ & $38,172(68)$ & Referent & & $30(10-60)$ & \\
\hline Medicare & $3041(31)$ & $12,639(23)$ & $1.57(1.50-1.65)$ & & $45(20-90)$ & \\
\hline Medicaid & $816(8)$ & $4447(8)$ & $1.20(1.11-1.30)$ & & $30(10-60)$ & \\
\hline None or other & $122(1)$ & 833 (1) & $0.96(0.79-1.16)$ & & $20(10-35)$ & \\
\hline Marital status & & & & $<0.001$ & & $<0.001$ \\
\hline Married & $5131(52)$ & $30,533(54)$ & Referent & & $30(10-65)$ & \\
\hline Single & $2954(30)$ & $17,792(32)$ & $0.99(0.94-1.04)$ & & $30(10-60)$ & \\
\hline Divorced/separated & $948(10)$ & $3752(7)$ & $1.50(1.39-1.62)$ & & $30(15-60)$ & \\
\hline Widowed & $569(6)$ & $2579(5)$ & $1.31(1.19-1.44)$ & & $45(25-90)$ & \\
\hline Unknown & $219(2)$ & $1435(2)$ & $0.91(0.79-1.05)$ & & $30(15-90)$ & \\
\hline Education & & & & $<0.001$ & & $<0.001$ \\
\hline Completed post-secondary & $5378(55)$ & $29,937(53)$ & Referent & & $30(10-60)$ & \\
\hline Some post-secondary & $1769(18)$ & $9256(17)$ & $1.06(1.00-1.13)$ & & $30(10-60)$ & \\
\hline Completed high school/GED & $1681(17)$ & $9697(17)$ & $0.97(0.91-1.02)$ & & $30(15-75)$ & \\
\hline Some high school & $291(3)$ & $1559(3)$ & $1.04(0.91-1.18)$ & & $30(15-90)$ & \\
\hline 8 th grade or less & $216(2)$ & $1404(3)$ & $0.86(0.74-0.99)$ & & $30(15-90)$ & \\
\hline Unknown & $486(5)$ & $4238(8)$ & $0.64(0.58-0.70)$ & & $30(10-60)$ & \\
\hline Diagnoses and other prescriptions & & & & & & \\
\hline Alcohol abuse & $292(3)$ & $1128(2)$ & $1.50(1.31-1.70)$ & $<0.001$ & $30(15-90)$ & 0.50 \\
\hline Antidepressant & $4345(44)$ & $9795(17)$ & $3.75(3.58-3.92)$ & $<0.001$ & $30(15-90)$ & $<0.001$ \\
\hline Anxiety & 3803 (39) & $5603(10)$ & $5.69(5.42-5.98)$ & $<0.001$ & $30(15-75)$ & $<0.001$ \\
\hline Asthma & $1788(18)$ & 7484 (13) & $1.45(1.37-1.53)$ & $<0.001$ & $30(15-90)$ & 0.004 \\
\hline COPD & $1727(18)$ & $6720(12)$ & $1.57(1.48-1.66)$ & $<0.001$ & $30(15-90)$ & $<0.001$ \\
\hline CVD & $2130(22)$ & $9154(16)$ & $1.42(1.35-1.50)$ & $<0.001$ & $30(15-90)$ & $<0.001$ \\
\hline Depression & $3077(31)$ & 8043 (14) & $2.73(2.60-2.86)$ & $<0.001$ & $30(15-90)$ & $<0.001$ \\
\hline Diabetes & $1250(13)$ & 7437 (13) & $0.95(0.89-1.02)$ & 0.15 & $30(15-90)$ & $<0.001$ \\
\hline Hypertension & $4133(42)$ & $21,113(38)$ & $1.20(1.15-1.26)$ & $<0.001$ & $30(15-90)$ & $<0.001$ \\
\hline Insomnia & $815(8)$ & $1588(3)$ & $3.11(2.84-3.39)$ & $<0.001$ & $30(20-90)$ & $<0.001$ \\
\hline Obesity & $1664(17)$ & 8707 (16) & $1.11(1.05-1.18)$ & $<0.001$ & $30(10-60)$ & 0.30 \\
\hline Osteoporosis & 1119 (11) & $4220(8)$ & $1.58(1.47-1.69)$ & $<0.001$ & $30(20-90)$ & $<0.001$ \\
\hline Sleep apnea & $730(7)$ & $2922(5)$ & $1.46(1.34-1.59)$ & $<0.001$ & $30(15-90)$ & 0.002 \\
\hline Substance abuse & $252(3)$ & $668(1)$ & $2.19(1.89-2.53)$ & $<0.001$ & $30(14-75)$ & 0.92 \\
\hline Tobacco use & $738(8)$ & $2611(5)$ & $1.66(1.53-1.81)$ & $<0.001$ & $30(15-90)$ & 0.03 \\
\hline
\end{tabular}

COPD chronic obstructive pulmonary disease; $C V D$ cardiovascular disease

*The OR for patient age is per decade

${ }^{\dagger}$ The OR for whites vs. non-whites receiving benzodiazepines was 2.05 (95\% confidence interval, 1.94-2.17)

${ }^{*}$ The referent for odds ratios for diagnoses and other prescriptions is patients who did not have that diagnosis or prescription

particularly when treatment is limited in dose and duration. ${ }^{34}$ Our finding that clinicians prescribed benzodiazepines disproportionately to patients with at least some known risk factors for benzodiazepine-related adverse events-including increased age, pulmonary diseases, osteoporosis, and substance use disorders - may help to explain the relationship between benzodiazepine use and poor health outcomes.

Benzodiazepines are associated with adverse effects, including higher mortality. ${ }^{3,4}$ Although causality has not been definitively determined, strong associations between benzodiazepine prescribing and mortality have been described in certain patient groups. Higher mortality rates have been found in patients with COPD, presumably due to respiratory suppression. ${ }^{5}$ Patients with opioid use disorders have a higher risk of overdose death — both suicide and non-suicide — when taking benzodiazepines. ${ }^{6,7,35}$ Senior patients are particularly vulnerable, because benzodiazepines are associated with falls, ${ }^{36-39}$ hip fractures, ${ }^{12}$ delirium, ${ }^{10,11}$ disability, ${ }^{13}$ dementia, ${ }^{14,15}$ and motor vehicle accidents. ${ }^{40}$ Osteoporosis has been linked to fractures alongside benzodiazepine prescriptions in 
Table 2 Utilization by Benzodiazepine Prescription and Dose

\begin{tabular}{|c|c|c|c|c|c|c|c|c|}
\hline & $\begin{array}{l}\text { Benzodiazepine } \\
\text { prescription } \\
(n=9831)\end{array}$ & $\begin{array}{l}\text { No } \\
\text { benzodiazepine } \\
\text { prescription } \\
(n=56,091)\end{array}$ & $\begin{array}{l}\text { Rate ratio } \\
(95 \% \\
\text { confidence } \\
\text { interval) }\end{array}$ & $P$ value & $\begin{array}{l}\text { High dose } \\
(n=481)\end{array}$ & $\begin{array}{l}\text { Standard } \\
\text { dose } \\
(n=9340)\end{array}$ & $\begin{array}{l}\text { Rate ratio } \\
(95 \% \\
\text { confidence } \\
\text { interval) }\end{array}$ & $P$ value \\
\hline \multicolumn{9}{|l|}{ Primary care visits* } \\
\hline $\begin{array}{l}\text { Primary care } \\
\text { physician visit rate } \\
\text { (per } 100 \text { patients) }\end{array}$ & 299 & 242 & $\begin{array}{l}1.23 \\
(1.22-1.25)\end{array}$ & $<0.001$ & 324 & 297 & $\begin{array}{l}1.12 \\
(1.07-1.18)\end{array}$ & $<0.001$ \\
\hline $\begin{array}{l}\text { Primary care clinic } \\
\text { visit rate (per } 100 \\
\text { patients) }\end{array}$ & 408 & 323 & $\begin{array}{l}1.26 \\
(1.25-1.28)\end{array}$ & $<0.001$ & 440 & 406 & $\begin{array}{l}1.12 \\
(1.07-1.17)\end{array}$ & $<0.001$ \\
\hline \multicolumn{9}{|c|}{ Specialist outpatient visits } \\
\hline $\begin{array}{l}\text { Patients with } \\
\text { specialist visits } \\
(\%)\end{array}$ & $9062(92)$ & 49,404 (88) & & $<0.001$ & $431(90)$ & $8631(92)$ & & 0.025 \\
\hline $\begin{array}{l}\text { Visit rate (per } 100 \\
\text { patients) }\end{array}$ & 815 & 578 & \multirow[t]{3}{*}{$\begin{array}{l}1.41 \\
(1.40-1.42)\end{array}$} & $<0.001$ & 887 & 810 & \multirow[t]{3}{*}{$\begin{array}{l}1.13 \\
(1.09-1.16)\end{array}$} & $<0.001$ \\
\hline Emergency visits & & & & & & & & \\
\hline $\begin{array}{l}\text { Patients with } \\
\text { emergency visits } \\
(\%)\end{array}$ & $2275(23)$ & 9433 (17) & & $<0.001$ & $144(30)$ & $2131(23)$ & & $<0.001$ \\
\hline $\begin{array}{l}\text { Visit rate (per } 100 \\
\text { patients) }\end{array}$ & 47 & 29 & \multirow[t]{3}{*}{$\begin{array}{l}1.62 \\
(1.56-1.67)\end{array}$} & $<0.001$ & 73 & 45 & \multirow[t]{3}{*}{$\begin{array}{l}1.66 \\
(1.49-1.85)\end{array}$} & $<0.001$ \\
\hline Hospitalizations & & & & & & & & \\
\hline $\begin{array}{l}\text { Patients with } \\
\text { hospitalizations } \\
(\%)\end{array}$ & $1202(12)$ & $4631(8)$ & & $<0.001$ & $88(18)$ & $1114(12)$ & & $<0.001$ \\
\hline $\begin{array}{r}\text { Hospitalization rate } \\
\text { (per } 100 \text { patients) }\end{array}$ & 26 & 15 & \multirow[t]{2}{*}{$\begin{array}{l}1.74 \\
(1.67-1.82)\end{array}$} & $<0.001$ & 44 & 25 & \multirow[t]{2}{*}{$\begin{array}{l}1.81 \\
(1.57-2.08)\end{array}$} & $<0.001$ \\
\hline Mean length of stay & 3.5 & 3.4 & & $<0.001$ & 3.1 & 3.3 & & 0.0052 \\
\hline
\end{tabular}

*All patients included in the analysis made at least one primary care visit

patients at risk of falls, although no direct relationship between osteoporosis and benzodiazepine prescriptions has been described. ${ }^{41,42}$ Prescribing benzodiazepines disproportionately to patients with COPD, substance use disorders, and osteoporosis, and who are older may contribute to their mortality risk through these mechanisms. Associations between benzodiazepines and tobacco use have been cited as a possible explanation for the association between benzodiazepines and cancer risk; ${ }^{8}$ our finding of a similar association supports the hypothesis that tobacco use confounds the relationship between benzodiazepines and the risk of cancer, although we did not measure cancer diagnoses directly, and this relationship remains poorly understood.

Our finding that high-dose prescribing was also associated with diagnoses of COPD and substance use disorders raises special concern. The magnitude of the association between benzodiazepines and mortality in general appears to be dose-dependent, 3,4 and dose-dependent relationships between benzodiazepines and mortality have been described independently for $\mathrm{COPD}^{5}$ and overdose deaths. ${ }^{43}$ Therefore, the disproportionate prescribing of high-dose benzodiazepines to patients with COPD and substance use disorders may amplify the effect of prescribing standard-dose benzodiazepines to patients already at risk of adverse outcomes.

The association between higher days dosed and receipt of Medicare may reflect an association between older age and longer benzodiazepine prescriptions, but we did not measure this directly and therefore cannot conclude that this is true. That clinicians prescribed shorter and fewer benzodiazepine prescriptions to black patients is notable, although we do not draw conclusions about medical risks of prescribing from this. We combined very brief prescriptions (e.g., single doses) with longer prescriptions in our analysis because mortality risk is associated with single benzodiazepine doses in a dose-response fashion. ${ }^{4,8}$

The increased frequency of medical diagnoses and higher rates of healthcare utilization associated with benzodiazepine prescriptions indicate that, in general, patients who receive benzodiazepines have higher levels of medical comorbidity. Prior studies in Brazil, the Netherlands, and Australia have linked benzodiazepine prescriptions - without a dose relationship - to patient selfreporting of poorer health status. ${ }^{21-23}$ Benzodiazepine prescriptions were similarly linked to higher frequencies of medical diagnoses in two population-based Canadian studies, ${ }^{40,41}$ and with a higher score on the Charlson comorbidity index in an Israeli study. ${ }^{18}$ Studies linking benzodiazepines to a higher number of medical visits ${ }^{21}$ and increased length of hospital stay ${ }^{26}$ have been conducted in Israel and Japan, respectively.

The fact that the use of benzodiazepines was associated with higher rates of inpatient and outpatient utilization in our study is consistent with two hypotheses: that patients with higher medical comorbidity are more likely to receive a benzodiazepine prescription, and that benzodiazepines may increase a patient's risk of adverse health outcomes. Both may be correct; our findings suggest a possible mechanism by which benzodiazepine prescriptions are associated with adverse outcomes for at least some patients.

\section{Limitations}

Our findings of an association do not necessarily signify causation. Some high-risk medical diagnoses such as respiratory illnesses ${ }^{44}$ and substance use disorders ${ }^{45}$ are associated 
Table 3 Patient Characteristics by Benzodiazepine Dose

\begin{tabular}{|c|c|c|c|c|}
\hline Characteristic & $\begin{array}{l}\text { High dose* } \\
(n=481)\end{array}$ & $\begin{array}{l}\text { Standard dose } \\
(n=9340)\end{array}$ & $\begin{array}{l}\text { Odds ratio } \\
\text { (95\% CI) }\end{array}$ & $P$ value \\
\hline & Mean $( \pm$ SD $)$ & & & \\
\hline Patient age, years & $51(13)$ & $55(15)$ & $0.81(0.77-0.86)^{\dagger}$ & $<0.001$ \\
\hline Number of medications & $\begin{array}{l}2.04(1.64) \\
\mathrm{N}(\%)\end{array}$ & $1.82(1.47)$ & $1.09(1.04-1.15)$ & $<0.001$ \\
\hline Patient gender & & & & $<0.001$ \\
\hline Men & $179(37)$ & $2520(27)$ & Referent & \\
\hline Women & $302(63)$ & $6820(73)$ & $0.62(0.52-0.75)$ & \\
\hline Patient race/ethnicity ${ }^{*}$ & & & & 0.28 \\
\hline White & $367(76)$ & $7240(78)$ & Referent & \\
\hline Black & $29(6)$ & $658(7)$ & $0.87(0.59-1.28)$ & \\
\hline Hispanic & $45(9)$ & $670(7)$ & $1.33(0.96-1.82)$ & \\
\hline Asian & $5(1)$ & 117 (1) & $0.84(0.34-2.08)$ & \\
\hline Other & $1(0)$ & $70(1)$ & $0.28(0.04-2.04)$ & \\
\hline Unknown & $34(7)$ & $585(6)$ & $1.15(0.80-1.65)$ & \\
\hline Language & & & & 0.39 \\
\hline English & $452(94)$ & $8751(94)$ & Referent & \\
\hline Spanish & $22(5)$ & 353 (4) & $1.21(0.78-1.88)$ & \\
\hline Other & $5(1)$ & $148(2)$ & $0.65(0.27-1.60)$ & \\
\hline Unknown & $2(0)$ & $88(1)$ & $0.44(0.11-1.79)$ & \\
\hline Insurance & & & & $<0.001$ \\
\hline Private & $220(46)$ & $5622(30)$ & Referent & \\
\hline Medicare & $154(32)$ & $2887(31)$ & $1.36(1.10-1.68)$ & \\
\hline Medicaid & $100(21)$ & $716(8)$ & $3.57(2.78-4.58)$ & \\
\hline None/other & $7(1)$ & $115(1)$ & $1.56(0.72-3.38)$ & \\
\hline Marital Status & & & & $<0.001$ \\
\hline Married & $260(43)$ & $4925(53)$ & Referent & \\
\hline Single & $191(40)$ & $2763(30)$ & $1.65(1.35-2.02)$ & \\
\hline Divorced/separated & $55(11)$ & $893(10)$ & $1.47(1.08-2.00)$ & \\
\hline Widowed & $17(4)$ & $552(6)$ & $0.74(0.45-1.22)$ & \\
\hline Unknown & $12(2)$ & $207(2)$ & $1.39(0.76-2.52)$ & \\
\hline Education & & & & $<0.001$ \\
\hline Completed post-secondary & $192(40)$ & $5186(56)$ & Referent & \\
\hline Some post-secondary & $121(25)$ & $1648(18)$ & $1.98(1.57-2.51)$ & \\
\hline Completed high school/GED & $96(20)$ & $1585(17)$ & $1.64(1.27-2.10)$ & \\
\hline Some high school & $36(7)$ & $255(3)$ & $3.81(2.61-5.56)$ & \\
\hline 8 th grade or less & $7(1)$ & $209(2)$ & $0.91(0.42-1.95)$ & \\
\hline Unknown & $29(6)$ & $457(5)$ & $1.71(1.15-2.56)$ & \\
\hline \multicolumn{5}{|l|}{ Diagnoses and other prescriptions ${ }^{\S}$} \\
\hline Alcohol abuse & $39(8)$ & $253(3)$ & $3.17(2.23-4.50)$ & $<0.001$ \\
\hline Antidepressant & $251(52)$ & $4094(44)$ & $1.40(1.16-1.68)$ & $<0.001$ \\
\hline Anxiety & $228(47)$ & $3575(38)$ & $1.45(1.21-1.75)$ & $<0.001$ \\
\hline Asthma & $110(23)$ & $1678(18)$ & $1.35(1.09-1.69)$ & 0.007 \\
\hline COPD & $117(24)$ & $1610(17)$ & $1.54(1.24-1.91)$ & $<0.001$ \\
\hline CVD & $99(21)$ & $2031(22)$ & $0.93(0.74-1.17)$ & 0.55 \\
\hline Depression & $201(42)$ & $2876(31)$ & $1.61(1.34-1.94)$ & $<0.001$ \\
\hline Diabetes & $70(15)$ & $1180(13)$ & $1.18(0.91-1.53)$ & 0.22 \\
\hline Hypertension & $201(42)$ & $3932(42)$ & 0.99 (0.82-1.19) & 0.89 \\
\hline Insomnia & $38(8)$ & $777(8)$ & $0.95(0.67-1.33)$ & 0.75 \\
\hline Obesity & $110(23)$ & $1554(17)$ & $1.49(1.19-1.85)$ & $<0.001$ \\
\hline Osteoporosis & $38(8)$ & $1081(12)$ & $0.66(0.47-0.92)$ & 0.013 \\
\hline Sleep apnea & $45(9)$ & $685(7)$ & $1.30(0.95-1.79)$ & 0.099 \\
\hline Substance abuse & 64 (13) & $188(2)$ & $7.47(5.53-10.09)$ & $<0.001$ \\
\hline Tobacco use & 82 (17) & $656(7)$ & $2.72(2.12-3.50)$ & $<0.001$ \\
\hline
\end{tabular}

COPD chronic obstructive pulmonary disease; CVD cardiovascular disease

*We defined high-dose benzodiazepine prescribing as a dose of $\geq 30 \mathrm{mg}$ per day of diazepam or equivalent

${ }^{+}$The OR for patient age is per decade

${ }^{*}$ The OR for whites vs. non-whites receiving a high benzodiazepine dose was 0.96 (95\% CI, $0.75-1.23$ )

${ }^{\S}$ The referent for odds ratios for diagnoses and other prescriptions is patients who did not have that diagnosis or prescription

with anxiety, which may be appropriate indications for a benzodiazepine prescription. Benzodiazepines may be employed directly to treat breathlessness, particularly as a palliative intervention at the end of life, although the evidence supporting a favorable risk/benefit ratio for this is limited, ${ }^{46}$ and we would expect these numbers to be small. Benzodiazepines also have a role in the treatment of alcohol withdrawal, although their use in alcohol disorders or withdrawal is not typically recommended in ambulatory settings. ${ }^{31}$ We did not record other medical indications for benzodiazepines such as muscle spasms. Our study relied on electronic documentation of information, which approximates but may not equal actual benzodiazepine use by patients. Our study could underestimate benzodiazepine use if patients receive care outside of our health system. Conversely, it could overestimate benzodiazepine use because we rely on prescribing data rather than filled prescriptions or claims. Because $56 \%$ of prescriptions came from providers outside primary care, and prescriptions from all 
providers were grouped together in our data, our findings may not reflect prescribing patterns for PCPs specifically, although we do not believe this detracts from the relevance of our findings. Our definition of high-dose benzodiazepine prescribing might be considered arbitrary, given the absence of clearly established potency comparisons between benzodiazepine agents; however, the cutoffs we used were close to other measurements of the 90th percentile of mean daily doses. ${ }^{33}$

\section{CONCLUSION}

We found that clinicians prescribed benzodiazepines more frequently to patients with known risk factors for benzodiazepine-related adverse events. Prescribers should take into account their patients' risk factors for adverse events when considering a benzodiazepine. For patients with COPD, substance use disorders, osteoporosis, and advanced agethose who appear to be the most likely to receive benzodiazepine prescriptions and, for the two former categories, at the highest doses - the choice of prescribing a benzodiazepine should be made with great caution.

ACKNOWLEDGMENTS: We acknowledge Joji Suzuki, MD, Brigham and Women's Hospital, for assistance with our study design.

Corresponding Author: David S. Kroll, MD; Department of Psychiatry, Brigham and Women's Hospital, 75 Francis Street, Boston, MA 02120, USA (e-mail: dskroll@partners.org).

\section{Compliance with Ethical Standards:}

Conflict of Interest: The authors declare that they do not have a conflict of interest.

\section{REFERENCES}

1. Voyer P, Cappeliez P, Perodeau G, Preville M. Mental health for older adults and benzodiazepine use. J Community Health Nurs. 2005:22(4):213-229.

2. Johnson DA. The use of benzodiazepines in depression. $\mathrm{Br} \mathrm{J}$ Clin Pharmacol. 1985;19(Suppl 1):31S-35S.

3. Weich S, Pearce HL, Croft P, et al. Effect of anxiolytic and hypnotic drug prescriptions on mortality hazards: retrospective cohort study. BMJ. 2014;348:g1996. doi:10.1136/bmj.g1996.

4. Kripke DF, Langer RD, Kline LE. Hypnotics' association with mortality and cancer: a matched cohort study. BMJ Open. 2012;2, e000850. doi:10. 1136/bmjopen-2012-00850.

5. Ekstrom MP, Bornefalk-Hermansson A, Abernethy AP, Currow DC. Safety of benzodiazepines and opioids in very severe respiratory disease: national prospective study. BMJ. 2014;348:g445. doi:10.1136/bmj.g445.6.

6. Hakkinen M, Launiainen T, Vuori E, Ojanpera I. Benzodiazepines and alcohol are associated with cases of fatal buprenorphine poisoning. Eur $\mathrm{J}$ Clin Pharmacol. 2012;68:301-309.

7. Lee SC, Klein-Schwartz W, Doyon S, Welsh C. Comparison of toxicity associated with nonmedical use of benzodiazepines with buprenorphine or methadone. Drug Alcohol Depend. 2014;138:118-123.

8. Kripke DF. Do hypnotic drugs cause cancer, like cigarettes? Sleep Med. 2015; 16:1550-1551.

9. Lavie P. Insomnia and sleep-disordered breathing. Sleep Med. 2007;8:S21-S25.

10. Rothberg MB, Herzig SJ, Pekow PS, Avrunin J, Lagu T, Lindenauer PK. Association between sedating medications and delirium in older patients. J Am Geriatr Soc. 2013;61:923-930.

11. MacPherson JA, Wagner CE, Boehm LM, et al. Delirium in the cardiovascular intensive care unit: exploring modifiable risk factors. Crit Care Med. 2013;41(2):405-413.
12. Khong TP, de Vries F, Goldenberg JS, et al. Potential impact of benzodiazepine use on the rate of hip fractures in five large European countries and the United States. Calcif Tissue Int. 2012;91:24-31.

13. Gray SL, LaCroix AZ, Hanlon JT, et al. Benzodiazepine use and physical disability in community-dwelling older adults. J Am Geriatr Soc. 2006;54(2):224-230.

14. DeGage SB, Moride Y, Ducruet T, et al. Benzodiazepine use and risk of Alzheimer's disease: case-control study. BMJ. 2014;349:g5205. doi:10. 1136/bmj.g5205.

15. Gallacher J, Elwood P, Pickering J, Bayer A, Fish M, Ben-Shlomo Y. Benzodiazepine use and risk of demential: evidence from the Caerphilly Prospective Study (CaPS). J Epidemiol Community Health. 2012;66:869873.

16. Vicens C, Bejarano F, Sempere E, et al. Comparative efficacy of two interventions to discontinue long-term benzodiazepine use: cluster randomised controlled trial in primary care. Br J Psychiatry. 2014;204:471-479.

17. Huerta C, Abbing-Karahagopian V, Requena G, et al. Exposure to benzodiazepines (anxiolytics, hypnotics and related drugs) in seven European electronic healthcare databases: a cross-national descriptive study from the PROTECT-EU Project. Pharmacoepidemiol Drug Saf. 2015. doi:10.1002/pds.3825.

18. Ayalon L, Gross R, Yaari A, Feldhamer E, Balicer RD, Goldfracht M. Patients' and physicians' characteristics associated with the purchase of benzodiazepines by older primary care patients in Israel. Adm Policy Ment Health. 2013;40:117-123.

19. Blazekovic-Milakovic S, Stojanovic-Spehar S, Katic M, Kumbrija S. Comparison of depression treatment among different age groups in primary care setting. Psychiatr Danub. 2011;23(2):183-188.

20. De las Cuevas C, Sanz E, De la Fuente JA, Cabrera C, Mateos A. Prescribed daily doses and 'risk factors' associated with the use of benzodiazepines in primary care. Pharmacoepidemiol Drug Saf. 1999;8:207-216.

21. Alvaraenga JM, Filho AI, Firmo Jo, Lima-Costa MF, Uchoa E. A population based study of health conditions associated with the use of benzodiazepines among older adults (The Bambui Health and Aging Study). Ca Saude Publica. 2009;25(3):605-612.

22. Darke S, Ross J, Mills $\mathbf{K}$, Teesson M, Williamson A, Havard A Benzodiazepine use among heroin users: baseline use, current use and clinical outcome. Drug Alcohol Rev. 2010;29:250-255.

23. Luijendijk HL, Tiemeier H, Hofman A, Heeringa J, Stricker BH. Determinants of chronic benzodiazepine use in the elderly: a longitudinal study. Br J Clin Pharmacol. 2007;65:593-599.

24. Cunningham CM, Hanley GE, Morgan S. Patterns in the use of benzodiazepines in British Columbia: examining the impact of increasing research and guideline cautions against long-term use. Health Policy. 2010;97:122-129.

25. Neutel CI. The epidemiology of long-term benzodiazepine use. Int Rev Psychiatry. 2005;17(3):189-197.

26. Nakao M, Sato M, Nomura K, Yano E. Benzodiazepine prescription and length of hospital stay at a Japanese university hospital. BioPsychoSocial Med. 2009;3:10.

27. Nalichowski R, Keogh D, Chueh HC, Murphy SN. Calculating the benefits of a research patient data repository. AMIA Annu Symp Proc. 2006: 1044 .

28. Persell SD, Friedberg MW, Meeker D, et al. Use of behavioral economics and social psychology to improve treatment of acute respiratory infections (BEARI): rationale and design of a cluster randomized controlled trial [1RC4AG039115-01]-study protocol and baseline practice and provider characteristics. BMC Infect Dis. 2013;13:290.

29. Meeker D, Linder JA, Fox CR, et al. Effect of behavioral interventions on inappropriate antibiotic prescribing among primary care practices: a randomized clinical trial. JAMA. 2016;315(6):562-570.

30. National Committee for Quality Assurance. HEDIS 2013 Measures. Available at: http://www.ncqa.org/Portals/0/HEDISQM/HEDIS2013/ List_of_HEDIS_2013_Measures_7.2.12.pdf. Accessed 25 Apr 2016.

31. Chick J, Nutt D. Substitution therapy for alcoholism: time for a reappraisal? J Psychopharmacol. 2012;26:205-12.

32. Cushman P, Benzer D. Benzodiazepines and drug abuse: clinical observations in chemically dependent persons before and during abstinence. Drug Alcohol Depend. 1980;6:365-371.

33. Hermos JA, Young MM, Lawler EV, Rosenbloom D, Fiore LD. Long-term, high-dose benzodiazepine prescriptions in veteran patients with PTSD: influence of preexisting alcoholism and drug-abuse diagnoses. J Trauma Stress. 2007;20(5):909-14.

34. Salzman C. The APA Task Force report on benzodiazepine dependence, toxicity, and abuse. Am J Psychiatr. 1991;148:151-152. 
35. Calcaterra S, Glanz J, Binswanger IA. National trends in pharmaceutical opioid related overdose deaths compared to other substance related overdose deaths: 1999-2000. Drug Alcohol Depend. 2013;131(3):263-270.

36. Heinrich S, Rapp K, Rissmann U, Becker C, Konig HH. Cost of falls in old age: a systematic review. Osteoporos Int. 2010;21:891-902.

37. Huang AR, Mallet L, Rochefort CM, Eguale T, Buckeridge DL, Tamblyn R. Medication-related falls in the elderly. Drugs Aging. 2012;29(5):359376.

38. Rossat A, Fantino B, Bongue B, et al. Association between benzodiazepines and recurrent falls: a cross-sectional elderly population-based study. J Nutr Health Aging. 2011;15(1):72-77.

39. Olazaran J, Valle D, Serra JA, Cano P, Ruben M. Psychotropic medications and falls in nursing homes: a cross-sectional study. JAMDA. 2013;14:213-217.

40. Johnell K, Laflamme L, Moller J, Monarrez-Espino J. The role of marital status in the association between benzodiazepines, psychotropics and injurious road traffic crashes: a register-based nationwide study of senior drivers in Sweden. PLoS One. 2014;9(1), e86742.
41. Pinheiro Mde M, Ciconelli RM, Martini LA, Ferraz MB. Risk factors for recurrent falls among Brazilian women and men: the Brazilian Osteoporosis Study (BRAZOS). Cad Saude Publica. 2010;26(1):89-96.

42. Cui Z, Schoenfeld MJ, Bush EN, Chen Y, Burge R. Characteristics of hip fracture patients with and without muscle atrophy/weakness: predictors of negative economic outcomes. J Med Econ. 2015;18(1):1-11.

43. Bachluber MA, Hennessy S, Cunningham CO, Starrels JL. Increasing benzodiazepine prescriptions and overdose mortality in the United States, 1996-2013. Am J Public Health. 2016;e1-e3. doi:10.2105/AJPH.2016. 303061.

44. Lavoie KL, Joseph M, Favreau H, et al. Prevalence of psychiatric disorders among patients investigated for occupational asthma. Am J Respir Crit Care Med. 2013;187(9):926-932.

45. Wolitzky-Taylor K, Bobova L, Zinbarg RE, Mineka S, Craske MG. Longitudinal investigation of the impact of anxiety and mood disorders in adolescence on subsequent substance use disorder onset and vice versa. Addict Behav. 2012;37(8):982-985.

46. Allcroft P, Margitanovic V, Greene A, et al. The role of benzodiazepines in breathlessness: a single site, open label pilot of sustained release morphine together with clonazepam. J Palliat Med. 2013;16(7):741-744. 